\title{
Jean-Pierre Proulx avec la collaboration de Christian Dessureault et Paul Aubin La genèse de l'école publique et de la démocratie scolaire au Québec. Les écoles de syndics 1814-1838
}

Québec: Les Presses de l'Université Laval, 2014. 504 p.

\author{
Andrée Dufour \\ Centre interuniversitaire d'études québécoises_Université Laval
}

C'est un défi important qu'entendaient relever l'auteur principal et ses collaborateurs de ce gros livre consacré à l'expérience des écoles de syndics. En effet, revoir les débuts de l'école publique et de la démocratie scolaire au Québec n'est pas une mince chose. Car le sujet avait déjà été traité, notamment pas Louis-Philippe Audet, grand historien de l'éducation, et repris plus récemment, entre autres, par Andrée Dufour. Toutefois, les auteurs ont voulu aller plus loin, s'efforçant de répondre à deux grandes interrogations : d'abord "pourquoi et comment a-t-on voulu confier la gouverne locale des écoles de campagne à des élus locaux » et non pas à un pouvoir central, puis comment cette démocratie scolaire " s'est implantée et s'est vécue sur le terrain de l'école même et à travers ses dimensions politiques, pédagogiques et administratives " (4). À cette fin, leur ouvrage se divise en deux grandes parties, soit " le projet politique " à l'origine des écoles de syndics et " la mise en œuvre " de ces écoles.

Dans la partie consacrée au projet politique, les auteurs examinent le Bas-Canada à l'époque des premières législations scolaires, au $19^{\mathrm{e}}$ siècle donc, en évoquant en premier lieu la démographie, l'économie, la propriété du sol et la production agricole, les classes sociales, la situation des femmes, celle de l'Église catholique et le contexte politique. Puis, ils font état des échecs en matière scolaire des années 1814-1827, pour ensuite évoquer l'objet central de leur étude, soit la courte expérience, l'essor et l'effondrement des écoles de syndics qui n'existèrent que de 1829 à 1836. Enfin, ils consacrent un chapitre respectif aux idéologies et aux influences extérieures qui ont marqué ce projet politique. 
C'est ensuite à la mise en œuvre du projet que s'attardent les auteurs, soit d'abord aux élections scolaires, aux élus, aux maisons d'école ainsi qu'aux instituteurs et institutrices. Ils évoquent également la pédagogie, la gouvernance et la gestion des écoles de même que leur mode de financement. Leurs constats sont multiples. Ainsi, ils établissent en premier lieu que les efforts du Bas-Canada en matière scolaire s'inscrivent dans un souci international de généralisation de l'éducation. Ils soulignent l'importance pour les éducateurs bas-canadiens des modèles étatsunien, écossais et de la Prusse notamment. Toutefois ils soulignent entre autres choses que le modèle éducatif mis en place en 1829 n'est pas « la réplique exacte d'aucun modèle étranger » (208), car le Bas-Canada se démarquait d'autres pays ou colonies du fait que son système éducatif «ne relevait pas d'une autorité centrale ». C'est que le Parti canadien et patriote refusait qu'il soit sous la responsabilité de l'exécutif, soit du pouvoir colonial, préférant confier à la Chambre d'assemblée et aux élites locales la surveillance des écoles.

Dans la seconde partie de leur ouvrage, les auteurs s'attardent à la mise en œuvre des écoles de syndics, une mise en œuvre étudiée à travers huit différents chapitres portant d'abord sur les élections des syndics et sur le statut socioprofessionnel de ces élus. Les "maisons d'école " puis le recrutement, la compétence et la rémunération des instituteurs et institutrices font l'objet des chapitres suivants. Enfin, l'examen de la pédagogie, de la gouvernance et de la gestion des écoles ainsi que leurs modes de financement font l'objet de chapitres distincts. Cette mise en œuvre, les auteurs l'admettent, "demeure pour une trop large part encore inconnue " (449). Elle fut cependant fort difficile, soutiennent-ils, les communautés locales n'ayant qu'une courte et faible expérience de la démocratie. Les syndics, notamment chargés de l'engagement des maîtres et de la gestion de l'école elle-même, appartenaient surtout à la notabilité. Ils étaient choisis, élus plutôt, parmi les représentants de la petite bourgeoisie, composée de notaires, de médecins et de marchands, de curés aussi, comme d'ailleurs de cultivateurs, " moyens » et " grands ». Il reste, comme le soutiennent les auteurs, que "l'école des syndics fut avant tout une école des communautés locales. » (456) Quant aux apprentissages des écoliers, faute de sources, on sait peu de choses. Sans doute étaient-ils limités, car une faible proportion des enfants âgés de six à treize ans, soit le quart des enfants alors d'âge scolaire, fréquentaient l'école, et ce, pendant peu de temps, en moyenne à peine plus de trois ans de fait.

Avec le succès que connurent les écoles de syndics, les auteurs rappellent que l'érection des maisons d'école et le paiement des maîtres représentèrent rapidement des coûts importants, "un défi particulièrement complexe pour l'État bas-canadien. " (456) La Chambre d'Assemblée souhaita donc partager le coût de l'éducation avec les parents d'écoliers par le moyen d'une contribution financière. La fréquentation scolaire chutant de façon importante, l'idée d'une taxe foncière ou d'une cotisation volontaire des communautés locales fut avancée mais non retenue " compte tenu de la mentalité populaire à propos de l'éducation » (457). L'intransigeance de Londres et du Conseil législatif signifièrent la fin de ce projet éducatif. Il n’en demeure pas moins, soutiennent les auteurs, qu'en dépit de leur brève existence — que sept ans —, les écoles de syndics furent le "fondement ", "la genèse » de l'école publique québécoise 
et de la démocratie scolaire au Québec, en confirmant, et ce, jusqu’à la Révolution tranquille, "la place prépondérante " des communautés locales en éducation. (458).

Fort bien écrit, reposant sur maintes études et la consultation de nombreuses sources manuscrites et imprimées, cet ouvrage s'avère en définitive une étude fouillée et une contribution importante à la connaissance de l'expérience des écoles de syndics et, plus globalement, de l'histoire de l'éducation au Québec. 